\title{
A gas diffusion sequential injection system for the determination of sulphur dioxide in wines
}

Keywords: Sequential injection; Sulphur dioxide; Wine; Gas diffusion; Spectrophotometry

\author{
Marcela A. Segundo, António O.S.S. Rangel* \\ Escola Superior de Biotecnologia, Universidade Católica Portuguesa, R. Dr. António Bernardino de Almeida, Porto 4200-072, Portugal
}

\begin{abstract}
In the present work, a sequential injection system with spectrophotometric detection was developed for the determination of free and total sulphur dioxide in wines. It was based on the formation of a coloured product from the reaction among $\mathrm{SO}_{2}$, formaldehyde and pararosaniline. A gas diffusion unit (GDU) was incorporated into the manifold to prevent the wine matrix interference in the spectrophotometric measurement. An acid solution was added to the sample prior to its passage through the donor channel of the GDU to promote gaseous $\mathrm{SO}_{2}$ formation. For the free $\mathrm{SO}_{2}$ determination, the sample was directly aspirated into the holding coil; for the total $\mathrm{SO}_{2}$ determination, the sample was processed after previous in-line hydrolysis of bound $\mathrm{SO}_{2}$ with an alkali solution.

Two second-order calibration curves were established, defining two concentration ranges: $2-40 \mathrm{mg} \mathrm{l}^{-1}$ for the free $\mathrm{SO}_{2}$ determination and $25-250 \mathrm{mg} \mathrm{l}^{-1}$ for the total $\mathrm{SO}_{2}$ determination. Relative standard deviations $(n=10)$ were lower than $1.2 \%$ for the determination of free $\mathrm{SO}_{2}$ and lower than $2.3 \%$ for the determination of total $\mathrm{SO}_{2}$. The sample frequency was about $16 \mathrm{~h}^{-1}$.

This methodology was applied to the determination of free and total sulphur dioxide in 10 table wines and the results were statistically comparable with those furnished by the recommended procedure. (C) 2001 Elsevier Science B.V. All rights reserved.
\end{abstract}

\section{Introduction}

Sulphur dioxide is added to wine during its production to prevent undesirable microbial growth and oxidation processes during the different steps involved. It is usually present in wine either free, as $\mathrm{HSO}_{3}{ }^{-}$ and $\mathrm{SO}_{2}$, or bound to carbonyl or unsaturated compounds and/or phenol derivatives. The determination of sulphur dioxide is routinely performed in wines for

${ }^{*}$ Corresponding author. Tel.: +351-22-5580064; fax: $+351-22-5090351$.

E-mail address: rangel@esb.ucp.pt (A.O.S.S. Rangel). different reasons. During production, the $\mathrm{SO}_{2}$ level must be controlled to avoid high concentrations, which give wines a disagreeable aroma and taste and also inhibits malolactic fermentation. The $\mathrm{SO}_{2}$ concentration must also be monitored and adjusted before bottling, since losses by diffusion, oxidation and binding occur during wine ageing. Finally, the $\mathrm{SO}_{2}$ concentration is also determined in the final product, since its maximum value is established by legislation in several countries [1].

Several automatic methods with spectrophotometric detection were already described in the literature 
to perform this determination in wines, resorting either to segmented flow analysis [2] or to flow injection analysis [3-10]. Nevertheless, some of them could not be applied to red wines $[3,4]$ or originated significant deviations when compared to the recommended procedure [11]. To overcome the problems caused by the coloured complex matrix, some authors proposed manifolds where it was possible to separate the analyte from the wine, by means of gas diffusion [4-6], microdistillation [7], pervaporation [8] or by using a gas generating and purging device [9].

Recently, sequential injection analysis (SIA) has been proposed by Ruzicka and Marshall [12] as a possible alternative to flow injection analysis (FIA). Some advantages, like lower reagent consumption and robustness, were pointed out to SIA when compared to FIA [13]. It was also considered a very versatile approach since a single SIA configuration can be adapted for multi-reagent techniques and multi-detection systems without the need of manifold reconfiguration [14].

In this paper, the determination of sulphur dioxide in wines was implemented using a SIA system. The main objective was to devise a single manifold with spectrophotometric detection to carry out the determination of free and total $\mathrm{SO}_{2}$ in both white and red table wines. The methodology chosen was based on the reaction among pararosaniline, formaldehyde and $\mathrm{SO}_{2}$ [15]. A gas diffusion unit (GDU) was incorporated into the manifold in order to separate the analyte in its gaseous form from the complex matrix. In previous SIA applications, the two channels of the GDU were connected to two different selection valves [16] or to two independent pumps [17]. In both cases, the carrier flowed through both channels simultaneously, like in a flow injection system. In another SIA system already described [18], the donor channel was connected to the selection valve and the acceptor channel was placed between two consecutive ports of a six port injection valve. In this way, the carrier passed through the donor channel while the content of the other channel remained trapped. On the present system, each channel was connected to a different port of the selection valve, allowing the same kind of operation, using a simpler system with just one valve.

\section{Experimental}

\subsection{Reagents and solutions}

All chemicals used were of analytical reagent grade with no further purification, and deionized water with a specific conductance less than $0.1 \mu \mathrm{S} \mathrm{cm}^{-1}$ was used throughout. The colour reagent was prepared by mixing $5 \mathrm{ml}$ of a concentrated pararosaniline solution, $1.7 \mathrm{ml}$ of $36 \%(\mathrm{~m} / \mathrm{m})$ hydrochloric acid (Merck) and $250 \mu \mathrm{l}$ of $37 \%(\mathrm{~m} / \mathrm{m})$ formaldehyde (Merck); the volume was completed to $25 \mathrm{ml}$ with water. To prepare the concentrated pararosaniline solution a $20 \mathrm{ml}$ volume of ethanol containing $0.10 \mathrm{~g}$ of pararosaniline hydrochloride (Sigma) was diluted with water to $100 \mathrm{ml}$.

The carrier solution was hydrochloric acid $0.8 \mathrm{moll}^{-1}$; the solution added to the sample in confluence X (Fig. 1) was also $\mathrm{HCl}$, but its concentration was $4 \mathrm{moll}^{-1}$. Both solutions were prepared by an appropriate dilution from the $36 \%(\mathrm{~m} / \mathrm{m})$ solution.

A $500 \mathrm{mg} \mathrm{l}^{-1}$ sulphur dioxide stock solution was prepared by weighing $0.250 \mathrm{~g}$ of $\mathrm{Na}_{2} \mathrm{SO}_{3}$ (Merck), which was dissolved in $250 \mathrm{ml}$ of a $0.001 \mathrm{moll}^{-1}$ EDTA (Merck) solution [19]; the stock solution was standardised daily by iodimetric titration. The working standard solutions were prepared daily from the previous solution by rigorous dilution in a $0.001 \mathrm{moll}^{-1}$ EDTA solution.

To assess the influence of $\mathrm{CO}_{2}$ in the determination, standards were prepared by appropriate dilution of a $10 \mathrm{~g} \mathrm{l}^{-1}$ stock solution (1.91 $\mathrm{g}$ of $\mathrm{NaHCO}_{3}$ (Merck) in $100 \mathrm{ml}$ of water).

For the determination of free $\mathrm{SO}_{2}$, the wine samples were inserted into the system without prior treatment. On the determination of total $\mathrm{SO}_{2}$, the release of the bound $\mathrm{SO}_{2}$ was required. During preliminary studies, this operation was carried out according to the rapid assay method recommended by Office International de la Vigne et du Vin (OIV) [11]. Therefore, $10.0 \mathrm{ml}$ of wine was previously alkalinised with $1.6 \mathrm{ml}$ of $4 \mathrm{~mol}^{-1} \mathrm{NaOH}$ (Merck) solution, before introduction into the system.

For in-line hydrolysis of bound $\mathrm{SO}_{2}$, a $2.5 \mathrm{moll}^{-1}$ sodium hydroxide solution was added to the sample. It was prepared by dissolving $10 \mathrm{~g}$ of $\mathrm{NaOH}$ pellets in $100 \mathrm{ml}$ of water. 


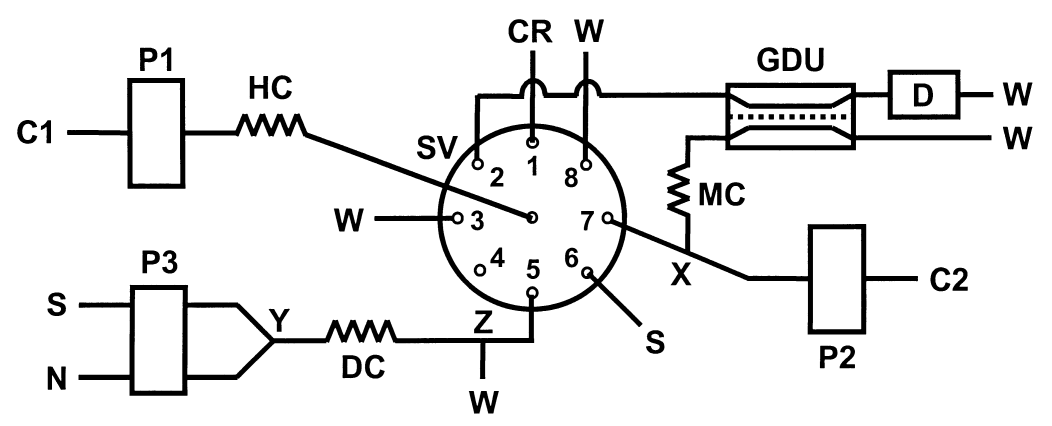

Fig. 1. SIA manifold for the determination of sulphur dioxide in wines. SV: selection valve; P1, P2, P3: peristaltic pumps; HC: holding coil; DC: dilution coil; MC: mixing coil; D: detection system; GDU: gas diffusion unit; C1: 0.8 mol $1^{-1}$ hydrochloric acid; C2: 4 mol $1^{-1}$ hydrochloric acid; $\mathrm{N}$ : $2.5 \mathrm{~mol}^{-1}$ sodium hydroxide; S: sample or standard; CR: colour reagent; W: waste; X, Y, Z: confluences.

\subsection{Apparatus}

The solutions were propelled by three different Gilson Minipuls 3 peristaltic pumps, equipped with Gilson PVC pumping tubes. One of the pumps was connected to the central channel of an eight port electrically actuated selection valve (Valco VICI C15-3118E).

A Unicam 8625 UV-VIS spectrophotometer equipped with a Helma 178.711QS flow-through cell (internal volume $30 \mu \mathrm{l}$ ) was used as detection system and the wavelength was set at $580 \mathrm{~nm}$. The analytical signals were recorded in a Kipp and Zonen BD 111 strip chart recorder.

The gas diffusion unit consisted of two acrylic blocks that were pressed against each other by four screws [20]. The gas diffusion hydrophobic membrane (Milipore, ref. GVHP, pore size $0.22 \mu \mathrm{m}$ ) was placed between the two blocks, separating two matching cavities ( $2 \mathrm{~mm}$ wide, $0.5 \mathrm{~mm}$ deep and $70 \mathrm{~mm}$ long), drilled in each block. The membrane was replaced daily.

A 386 personal computer (Samsung SD700) equipped with an Advantec PCL818L interface card, running a homemade software written in QuickBasic 4.5 (Microsoft), controlled the selection valve position and both the rotation sense and speed of the peristaltic pumps.

\subsection{Manifold}

Manifolds were made from Omnifit PTFE tubing (0.8 mm i.d.) with Gilson end-fittings and connectors.
Laboratory made acrylic Y-shaped joints were used as confluences. The system components were arranged as shown schematically in Fig. 1.

The holding coil (HC) length and the digestion coil (DC) length were both $200 \mathrm{~cm}$ long. The connection between the valve and the acceptor channel of the gas diffusion unit (GDU) was $2.5 \mathrm{~cm}$ long. The sample tubing connected to the confluence $\mathrm{Z}$ was also $2.5 \mathrm{~cm}$ long. Both the mixing coil (MC) and the connection between the valve and confluence $X$ were $20 \mathrm{~cm}$ long. The connection between the acceptor channel of the GDU and the flow cell was $60 \mathrm{~cm}$ long. Other tubing connected to the valve were $20 \mathrm{~cm}$ long.

\subsection{Sequential injection procedure}

The protocol of flow and timing sequence for the determination of sulphur dioxide in wines is listed in Table 1; different conditions were used for the determination of free or total $\mathrm{SO}_{2}$.

The analytical cycle started with the colour reagent aspiration into the HC. After selection of the proper port, the flow was reversed and the colour reagent was placed in the acceptor side of the gas diffusion membrane. Next, the content of the HC was flushed with carrier to the waste to eliminate any colour reagent remains. The next step was the sample aspiration. For the determination of free $\mathrm{SO}_{2}$, the sample was directly aspirated into the $\mathrm{HC}$; for the determination of total $\mathrm{SO}_{2}$, the release of bound $\mathrm{SO}_{2}$ was required. So, the hydrolysis of bound $\mathrm{SO}_{2}$ was carried out in-line with addition of an alkali solution $\left(0.18 \mathrm{ml} \mathrm{min}^{-1}\right)$ to the sample $\left(0.87 \mathrm{ml} \mathrm{min}^{-1}\right)$ in confluence $\mathrm{Y}$ prior to its 
Table 1

Protocol sequence for the determination of sulphur dioxide in wines ${ }^{\mathrm{a}}$

\begin{tabular}{|c|c|c|c|c|c|}
\hline Step & $\begin{array}{l}\text { Valve } \\
\text { position }\end{array}$ & $\begin{array}{l}\text { Operation } \\
\text { time }(s)\end{array}$ & 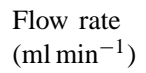 & $\begin{array}{l}\text { Volume } \\
(\mu \mathrm{l})\end{array}$ & Description \\
\hline a & 1 & 10 & 1.7 & 287 & Aspirate colour reagent to holding coil \\
\hline $\mathrm{b}$ & 2 & 10 & 1.1 & 185 & $\begin{array}{l}\text { Dispense holding coil content to the acceptor } \\
\text { channel of the GDU }\end{array}$ \\
\hline $\mathrm{c}$ & 3 & 10 & 4.4 & 733 & Flush holding coil \\
\hline $\mathrm{d}$ & $6 / 5^{\mathrm{b}}$ & $10 / 25^{\mathrm{b}}$ & $1.1 / 0.6^{\mathrm{b}}$ & $190 / 238^{b}$ & Aspirate sample or standard \\
\hline$e^{c}$ & 7 & $20 / 15^{\mathrm{b}}$ & 0.8 & $280 / 210^{\mathrm{b}}$ & $\begin{array}{l}\text { Dispense sample through the donor channel of GDU, } \\
\text { with addition of acid in confluence } \mathrm{X}\end{array}$ \\
\hline $\mathrm{f}$ & 8 & $10 / 6^{\mathrm{b}}$ & 4.4 & $736 / 445^{b}$ & Flush holding coil to remove sample residues \\
\hline $\mathrm{g}$ & 2 & 60 & 2.2 & 2223 & Propel reaction product to detector, signal registration \\
\hline $\mathrm{h}$ & 7 & 20 & 3.3 & 1116 & Dispense carrier to wash GDU donor channel \\
\hline $\mathrm{i}$ & 2 & 15 & 3.3 & 838 & Dispense carrier to wash GDU acceptor channel \\
\hline $\mathrm{j}^{\mathrm{d}}$ & 5 & 4 & 1.7 & 112 & Dispense carrier to wash sample tubing \\
\hline
\end{tabular}

a Values of flow rate refer to pump 1.

b Parameters with different values for determination of free and total $\mathrm{SO}_{2}$, respectively.

${ }^{c}$ The volume of acid added was different for each determination: $83 \mu$ l for the determination of free $\mathrm{SO}_{2}$ and $300 \mu 1$ for determination of total $\mathrm{SO}_{2}$.

${ }^{\mathrm{d}}$ Step executed only for the total $\mathrm{SO}_{2}$ determination.

aspiration (Fig. 1, port 5). During the rest of the analytical cycle, the digested sample was discarded to the waste through confluence $\mathrm{Z}$.

After sample aspiration, the flow was again reversed and the sample was propelled through the donor channel of the GDU. During this step, pump 2 was activated and acid was added to the sample to promote the formation of gaseous $\mathrm{SO}_{2}$ and its passage across the diffusion membrane. After HC flush to the waste, the reaction product formed in the acceptor channel of the GDU was propelled to the spectrophotometer.

Finally, to prepare the system for a new analytical cycle, carrier was sequentially propelled through both donor and acceptor channels of the GDU. In the determination of total $\mathrm{SO}_{2}$, the sample tubing (port 5) was also flushed.

During preliminary studies, the bound $\mathrm{SO}_{2}$ alkali digestion was performed outside the system. So, the parameters of steps (d) and (e) (Table 1) were modified; the volume of sample aspirated was $229 \mu \mathrm{l}$ at $1.1 \mathrm{ml} \mathrm{min}^{-1}$; it was dispensed $267 \mu \mathrm{l}$ at $0.8 \mathrm{ml} \mathrm{min}^{-1}$ through the donor channel of the GDU, with addition of $800 \mu \mathrm{l}$ of acid from pump 2 at $2.4 \mathrm{ml} \mathrm{min}^{-1}$. The other steps were the same described for the determination of free $\mathrm{SO}_{2}$. The volumes were obtained by performing the operation step 10 times and weighing the water aspirated from or dispensed into a previous zeroed beaker.

\subsection{Recommended procedure}

For the determination of free $\mathrm{SO}_{2}$, the recommended procedure by OIV [11] involved a direct titration of iodine, using starch for detection of the end-point. For the determination of total $\mathrm{SO}_{2}$, the same procedure was applied with a prior alkaline hydrolysis to release the bound $\mathrm{SO}_{2}$.

\section{Results and discussion}

\subsection{Development of the sequential injection system}

\subsubsection{Preliminary studies}

Preliminary experiments were carried out without addition of acid in confluence $X$. Acidification of sample was achieved only by mixing sample and carrier during sample aspiration and flow reversal. Alkalinised standards $\left(1-30 \mathrm{mg}^{-1}\right.$ in $\left.\mathrm{SO}_{2}\right)$, with $0.5 \mathrm{moll}^{-1}$ in $\mathrm{NaOH}$, were tested. The signals obtained were lower than those obtained for regular standards. Even when the acid concentration in the carrier was raised (from 0.8 to $1.2 \mathrm{moll}^{-1}$ ), the same effect was verified. So, to achieve effective acidification of the sample plug, pump 2 and confluence $\mathrm{X}$ had to be added to the manifold, allowing the addition of acid along the sample plug before it passed by the gas diffusion membrane. 
The flow rate used in pump 1 was set as a compromise between quickness and efficiency (values in Table 1). For instance, when flushing the HC, the highest flow rate $\left(4.4 \mathrm{ml} \mathrm{min}^{-1}\right)$ was used, but for washing the GDU, the flow rate used was $3.3 \mathrm{ml} \mathrm{min}^{-1}$; higher values increased backpressure at the GDU.

The colour reagent volume aspirated and the volume propelled to GDU were set to 287 and $185 \mu \mathrm{l}$, respectively. These values were sufficient to have colour reagent in contact with all the acceptor side of the gas diffusion membrane. The other volumes used (Table 1) were kept as low as possible.

The proportion of acid added to the sample in confluence $\mathrm{X}$ was established by the flow rate used in pump 2, since the flow rate of pump $1\left(0.8 \mathrm{ml} \mathrm{min}^{-1}\right)$ was the same for both determinations. In the determination of free $\mathrm{SO}_{2}$, the chosen proportion was one part of acid to three parts of sample, using a flow rate of $0.25 \mathrm{ml} \mathrm{min}^{-1}$ in pump 2 . In the determination of total $\mathrm{SO}_{2}$, the flow rate was raised to $1.2 \mathrm{ml} \mathrm{min}^{-1}$, originating a proportion of four parts of acid to three parts of sample. On one hand, this condition was changed to achieve determination in concentrations higher than those attained for the determination of free $\mathrm{SO}_{2}$. This was a consequence of two different effects: the sample was more diluted and it was less time in contact with the diffusion membrane. Both situations lowered the efficiency of gas diffusion through the membrane [21]. On the other hand, as the digested sample was alkaline, a higher amount of acid should be added to convert the analyte to its gaseous form.

\subsubsection{Optimisation of chemical variables}

With the above stated values set, optimisation of chemical variables were carried out by the univariate method. The mixing coil length was kept to $20 \mathrm{~cm}$ and the concentration of $\mathrm{HCl}$ in the carrier solution and in the colour reagent were both set to $0.8 \mathrm{~mol}^{-1}$. Firstly, the concentration of pararosaniline and formaldehyde in the colour reagent were both studied. The assessment comprised the establishment of calibration curves using the conditions for the determination of free $\mathrm{SO}_{2}$ (Table 1) and standards with concentrations between 2 and $40 \mathrm{mg} \mathrm{l}^{-1}$.

The influence of the pararosaniline concentration was evaluated between 0.05 and $0.40 \mathrm{~g} \mathrm{l}^{-1}$ by keeping the formaldehyde concentration to $4.0 \mathrm{~g} \mathrm{l}^{-1}$. As the pararosaniline concentration was risen, the sensitivity increased, as well as the blank signal. So, the chosen concentration of $0.20 \mathrm{~g} \mathrm{l}^{-1}$ was a compromise between these two effects.

The formaldehyde concentration was studied between 1.0 and $8.0 \mathrm{gl}^{-1}$, while the pararosaniline concentration was maintained in $0.20 \mathrm{gl}^{-1}$. The results obtained indicated an increase in sensitivity with the concentration increase. However, the concentration chosen was $4.0 \mathrm{gl}^{-1}$, since higher concentrations originated precipitate deposition inside the valve and tubing.

The influence of $\mathrm{HCl}$ concentration in the solution added in confluence $\mathrm{X}$ was studied between 1 and $6 \mathrm{moll}^{-1}$. The conditions used were those for the determination of total $\mathrm{SO}_{2}$ with sample digestion outside the system. Similar calibration curves were obtained whatever concentration used. When white wine samples were introduced into the system, lower signals were obtained up to the $2 \mathrm{moll}^{-1} \mathrm{HCl}$ solution. For the red wine samples tested, the analytical signal was the same just for solutions with concentration equal to or higher than $4 \mathrm{moll}^{-1}$, therefore, this was the chosen concentration.

\subsubsection{Optimisation of the mixing coil length}

With the chemical variables set at the stated values, the length of the connection between confluence $\mathrm{X}$ and the donor channel of the GDU was changed to 20, 50 and $80 \mathrm{~cm}$. The operation time for step (e) (Table 1) was increased for the longer connections in order to assure that the whole sample plug passed through the donor side of the membrane. The influence of the connection length was assessed for both determinations. For the determination of total $\mathrm{SO}_{2}$, the sample was previously digested outside the system; the calibration curves obtained were similar for all connections used but, when wine samples were tested, the signals obtained for the $80 \mathrm{~cm}$ connection were lower than those provided by the other two tubing. For the determination of free $\mathrm{SO}_{2}$, the values of the analytical signal for the 50 and $80 \mathrm{~cm}$ connection were equivalent to $70-75 \%$ of the value obtained for the $20 \mathrm{~cm}$ connection. Therefore, the connection chosen was $20 \mathrm{~cm}$ long.

\subsubsection{In-line digestion}

With the previous conditions set, the step of in-line digestion of the sample was introduced. The mixing 
proportion in confluence Y (Fig. 1) was one part of alkali solution to 4.8 parts of sample.

\subsubsection{Interference study}

As previously reported [22], carbon dioxide affects the passage of sulphur dioxide across the gas diffusion membrane. In order to assess its influence, 10 and $20 \mathrm{mg} \mathrm{l}^{-1} \mathrm{SO}_{2}$ standards were prepared with 0, 1000, 2000 and $3000 \mathrm{mg} \mathrm{l}^{-1}$ of $\mathrm{CO}_{2}$, they were analysed using the conditions for the determination of free $\mathrm{SO}_{2}$. The signals for both standards containing 0, 1000 and $2000 \mathrm{mg} \mathrm{1}^{-1}$ in $\mathrm{CO}_{2}$ were similar, except that the latter presented poor repeatability. Both standards containing $3000 \mathrm{mg} \mathrm{l}^{-1}$ in $\mathrm{CO}_{2}$ gave rise to bubble formation during sample aspiration, affecting the repeatability of the signals obtained.

\subsection{Evaluation of the method and its application to wine samples}

The performance of the proposed system for the determination of free and total sulphur dioxide in wines was evaluated regarding to application range, detection limit, sample frequency, accuracy and repeatability.

Using the same manifold, two second-order calibration curves were established, defining two concentration ranges, one for each determination. The standards concentration varied between 2 and $40 \mathrm{mg} \mathrm{l}^{-1}$ (free $\mathrm{SO}_{2}$ ) and between 25 and $250 \mathrm{mg} \mathrm{l}^{-1}$ (total $\mathrm{SO}_{2}$ ).

\subsubsection{Detection limit}

The detection limit was calculated as the concentration corresponding to the intercept value plus three times the standard deviation of 10 consecutive blank injections [23]. The blank signal was obtained by injecting solutions with the same composition as the standards, except for the sulphur dioxide. For the free $\mathrm{SO}_{2}$ determination, the calculated detection limit was $0.1 \mathrm{mg} \mathrm{l}^{-1}$; for the total $\mathrm{SO}_{2}$ determination, the detection limit was $0.6 \mathrm{mg} \mathrm{l}^{-1}$.

\subsubsection{Sample throughput}

The sample frequency was different for each determination. The time required for a complete analytical cycle is not merely the summation of the time required for each step performance. The time required for the proper port selection in the selection valve must also be accounted. Considering this, the time required to
Table 2

Results $\left(\mathrm{mg}^{-1}\right)$ obtained by the proposed methodology $\left(C_{\mathrm{p}}\right)$ and by the recommended procedure $\left(C_{\mathrm{r}}\right)$ for the determination of total and free $\mathrm{SO}_{2}{ }^{\mathrm{a}}$

\begin{tabular}{|c|c|c|c|c|}
\hline \multirow[t]{2}{*}{ Sample } & \multicolumn{2}{|c|}{ Total $\mathrm{SO}_{2}$} & \multicolumn{2}{|c|}{ free $\mathrm{SO}_{2}$} \\
\hline & $C_{\mathrm{r}}$ & $C_{\mathrm{p}}$ & $C_{\mathrm{r}}$ & $C_{\mathrm{p}}$ \\
\hline 1 & 131 & 125 & 24.6 & 24.5 \\
\hline 2 & 173 & 176 & 21.2 & 21.2 \\
\hline 3 & 117 & 118 & 30.7 & 29.8 \\
\hline 4 & 162 & 173 & 25.7 & 24.4 \\
\hline 5 & 91.5 & 87.8 & 12.8 & 14.6 \\
\hline 6 & 139 & 147 & 16.4 & 17.8 \\
\hline 7 & 140 & 138 & 22.8 & 22.5 \\
\hline 8 & 150 & 149 & 17.6 & 16.4 \\
\hline 9 & 111 & 102 & 8.7 & 9.2 \\
\hline 10 & 125 & 114 & 24.0 & 22.5 \\
\hline
\end{tabular}

${ }^{a}$ White wines: 1-6; red wines: 7-10.

complete an analytical cycle was 209 s for the determination of free $\mathrm{SO}_{2}$ and $223 \mathrm{~s}$ for the determination of total $\mathrm{SO}_{2}$. The sample frequency was 17 and 16 determinations per hour, respectively.

\subsubsection{Comparison with the recommended procedure}

In order to evaluate the accuracy of the proposed system, it was applied to the determination of free and total sulphur dioxide in 10 table wines. The results $\left(C_{\mathrm{p}}\right)$ were compared with those furnished by the recommended procedure [11] $\left(C_{\mathrm{r}}\right)$, they are presented in the Table 2. A recorder output corresponding to the injection of a set of standards and wine samples is presented in Fig. 2.

For comparison purposes, a linear relationship $\left(C_{\mathrm{p}}=C_{0}+S C_{\mathrm{r}}\right)$ was established. The equation parameters, as well as the $95 \%$ confidence limits, are presented in Table 3. From these figures it is clear that the estimated slope and intercept do not differ significantly from the values 1 and 0 , respectively. Thus, there is no evidence for systematic differences between the two set of results [24] obtained by the proposed methodology and by the recommended procedure, for both determinations.

\subsubsection{Repeatability}

It was estimated by calculating the relative standard deviation from 10 consecutive injections of wine samples. Relative standard deviations were lower than $1.2 \%$ for the determination of free $\mathrm{SO}_{2}$ and lower than $2.3 \%$ for the determination of total $\mathrm{SO}_{2}$ (Table 3 ). 


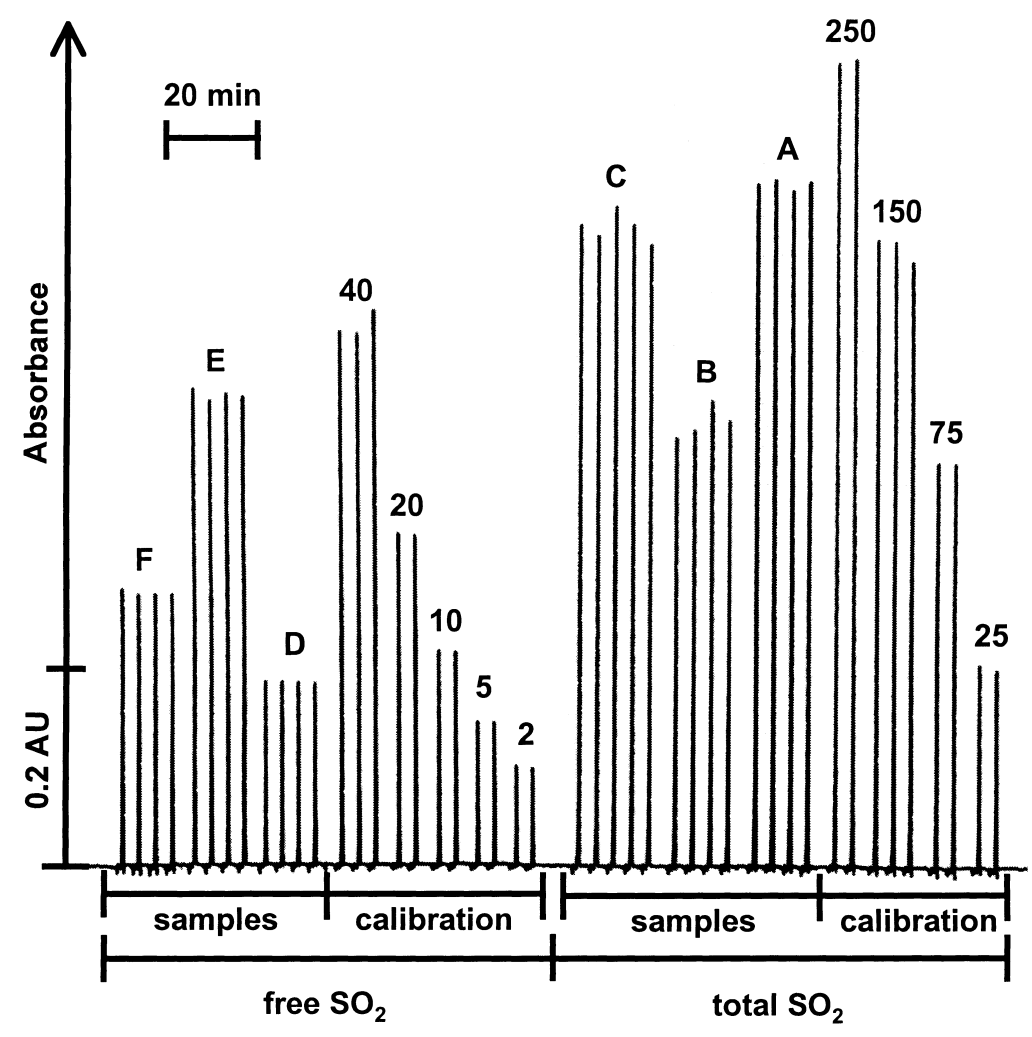

Fig. 2. Sequential injection register for the determination of free and total $\mathrm{SO}_{2}$, including a set of standards and table wine samples. The standards concentration are expressed in $\mathrm{mgl}^{-1}$. A, B, D, E: white wines; C, F: red wines.

Table 3

Parameters of the equation $C_{\mathrm{p}}=C_{0}+S C_{\mathrm{r}}$ for comparing the results $\left(\mathrm{mg}^{-1}\right)$ obtained by the proposed methodology $\left(C_{\mathrm{p}}\right)$ and by the recommended procedure $\left(C_{\mathrm{r}}\right)$, and the values for relative standard deviation $(n=10)$ for wine samples

\begin{tabular}{llll}
\hline & $C_{0}$ & $S$ & R.S.D. $^{\mathrm{a}}(\%)$ \\
\hline Free $\mathrm{SO}_{2}$ & 0.407 & 0.958 & $1.2(10.3)$ \\
& $( \pm 1.903)^{\mathrm{b}}$ & $( \pm 0.090)^{\mathrm{b}}$ & $0.8(23.0)$ \\
Total $\mathrm{SO}_{2}$ & -22.90 & 1.164 & $2.3(164)$ \\
& $( \pm 25.51)^{\mathrm{b}}$ & $( \pm 0.188)^{\mathrm{b}}$ & $1.5(69.4)$ \\
\hline
\end{tabular}

${ }^{a}$ Relative standard deviation measured for four different wines, with the respective concentration $\left(\mathrm{mg} \mathrm{l}^{-1}\right)$ between parentheses.

${ }^{b}$ The values in parentheses are the limits of the $95 \%$ confidence intervals.

\section{Conclusions}

In the present work, the sequential injection system developed allowed the determination of free and total
$\mathrm{SO}_{2}$ in both white and red wines. The same manifold was used for both determinations, just by introducing different parameters in the controlling software and performing a previous in-line sample digestion for the total determination. When the proposed SI system is compared to previously described FI systems for the same determination, the following advantages could be pointed out: both free and total forms can be assessed [5,9]; the system can be applied to red wines $[3,4]$ and the samples are directly aspirated into the system, without dilution or standard addition [6]. However, the system was not suitable for the determination in sparkling wines, since high levels of $\mathrm{CO}_{2}$ gave rise to bubble formation inside the PTFE tubing.

In the described manifold, each channel of the gas diffusion unit was connected to a different port of the selection valve. This simple configuration was successfully applied, without the flowing out problem reported by Oms et al. [18]. 
Despite the need of daily replacement of the GD membrane, the GDU was an effective mean to separate the analyte from the complex wine matrix, originating results with lower relative standard deviation than those obtained by the microdestillation [7] and the gas generation and purging device [9] used in previous FIA systems. The pervaporation-FI system described [8] also presented a low relative standard deviation, but the sample throughput was lower $\left(6-12 \mathrm{~h}^{-1}\right)$ when compared to the proposed system.

In SIA systems, as reagents and sample are sequentially aspirated into the $\mathrm{HC}$, the volumes used are normally lower when compared to conventional FIA systems, where they are pumped continuously. This is an important feature in SIA systems, not only because reagents are saved, but mostly when toxic reagents are handled, like pararosaniline. The low consumption of this reagent in the present system is an advantage when compared to previously described flow systems $[2,10,22]$.

The proposed system could also be suitable for process control during wine production. Its application could be done by connecting the sampling ports of the selection valve to the fermentation reactor. For the determination of free $\mathrm{SO}_{2}$, the sample from the reactor could be directly aspirated into the $\mathrm{HC}$; for the determination of total $\mathrm{SO}_{2}$, pump 3 could be activated whenever sampling was required, without continuous aspiration of the reactor content.

\section{Acknowledgements}

The authors acknowledge the financial support from PRAXIS XXI/Agência de Inovação through Project P076-P31B-09/97-INSIA. M.A. Segundo thanks FCT for the grant PRAXIS XXI BD/13648/97.

\section{References}

[1] M.A. Amerine, C.S. Ough, Methods for Analysis of Musts and Wines, Wiley, New York, 1980.
[2] F. Falcone, K.C. Maxwell, J. Agric. Food Chem. 40 (1992) 1355.

[3] P. Richter, M.D. Luque de Castro, M. Valcárcel, Anal. Chim. Acta 283 (1993) 408.

[4] J.J. Sullivan, T.A. Hollingworth, M.M. Wekell, V.A. Meo, H.H. Saba, A. Etemad-Moghadam, C. Eklund, J.G. Phillips, B.H. Gump, J. Assoc. Off. Anal. Chem. 73 (1990) 35.

[5] L.G. Decnop-Weever, J.C. Kraak, Anal. Chim. Acta 337 (1997) 125.

[6] R.L.G.N.P. Silva, C.S. Silva, J.A. Nóbrega, E.A. Neves, Anal. Lett. 31 (1998) 2195.

[7] A. Maquieira, F. Casamayor, R. Puchades, S. Sagrado, Anal. Chim. Acta 283 (1993) 401.

[8] E. Mataix, M.D. Luque de Castro, Analyst 123 (1998) 1547.

[9] Z. Zhi, A. Ríos, M. Valcárcel, Analyst 120 (1995) 2013.

[10] F. Lázaro, M.D. Luque de Castro, M. Valcárcel, Anal. Chem. 59 (1987) 950.

[11] Office International de la Vigne et du Vin (OIV), Recueil des Méthodes Internationales d'Analyse des Vins et des Moûts, OIV, 1990.

[12] J. Ruzicka, G.D. Marshall, Anal. Chim. Acta 237 (1990) 329.

[13] V. Cerdà, J.M. Estela, R. Forteza, A. Cladera, E. Becerra, P. Altimira, P. Sitjar, Talanta 50 (1999) 695.

[14] R.E. Taljaard, J.F. van Staden, Lab. Robot. Autom. 10 (1998) 325.

[15] P.W. West, G.C. Gaeke, Anal. Chem. 28 (1956) 1816.

[16] I. Lukkari, J. Ruzicka, G.D. Christian, Fresenius J. Anal. Chem. 346 (1993) 813.

[17] R.T. Echols, R.R. James, J.H. Aldstadt, Analyst 122 (1997) 315.

[18] M.T. Oms, A. Cerdà, A. Cladera, V. Cerdà, R. Forteza, Anal. Chim. Acta 318 (1996) 251.

[19] W. Frenzel, B. Hillmann, Chem. Anal. (Warsaw) 40 (1995) 619.

[20] J.L.F.C. Lima, O.B.A.O. Neves, A.O.S.S. Rangel, Flow injection determination of reducing sugar in wine in a wide concentration range using a dialysis unit and a stream splitting, in: J.J. Bimbenet, E. Dumoulin, G. Trystram (Eds.), Automatic Control of Food and Biological Processes, Elsevier, Amsterdam, 1994, pp. 67-74.

[21] V. Kubán, Critic. Rev. Anal. Chem. 23 (1992) 323.

[22] P. Linares, M.D. Luque de Castro, M. Valcárcel, Anal. Chim. Acta 225 (1989) 443.

[23] International Union of Pure and Applied Chemistry (IUPAC), Anal. Chem. 48 (1976) 2294.

[24] J.C. Miller, J.N. Miller, Statistics for Analytical Chemistry, 3rd Edition, Ellis Horwood, New York, 1993. 